\title{
Manual de biossegurança em Saúde: Vídeos para comunidade surda brasileira com novos termos em Libras empregados no cotidiano da pandemia do novo coronavírus
}

\author{
Bilingual biosafety manual: Videos produced for the brazilian deaf community with terms used in
} health services during the coronavirus pandemic

Manual de bioseguridad en Salud: Videos para la comunidad sorda brasileña con nuevos términos en LIBRAS empleados en el cotidiano de la pandemia del nuevo coronavirus

\section{Resumo}

Atualmente, com a pandemia do novo coronavírus, tornou-se cada dia mais frequente o uso de termos técnicos de biossegurança utilizados na área de saúde e em laboratórios de pesquisa. Entretanto, muitos desses termos utilizados em português ainda não existem na Língua Brasileira de Sinais - Libras, o que gera a falta de compreensão dos termos, traz riscos à saúde dos surdos e dificulta a comunicação com os profissionais de saúde. Dessa forma, torna-se fundamental a preparação de materiais bilíngues (Libras-português) na área de biossegurança. O objetivo desta pesquisa é apresentar um manual bilíngue com novos termos em Libras, em formato de vídeo, como uma ferramenta que permite a comunicação e a capacitação dos surdos e dos profissionais de saúde. Metodologia: A seleção dos termos utilizados na elaboração do manual foi feita com base em mídias, jornais e literatura especializada com base no método de revisão sistemática descritiva. Foram selecionados 10 temas para a elaboração dos vídeos explicativos do manual. A validação das novas palavras em Libras foi realizada com um grupo de pesquisa do INES. Os vídeos foram disponibilizados em plataformas de Biocinais. Resultado: Observamos um alto número de acesso aos vídeos que explicam os conceitos de biossegurança, EPI e EPC. Conclusão: Os resultados preliminares demonstram que a construção de manuais que facilitem o entendimento dos surdos sobre a biossegurança e a comunicação deles com os profissionais da área de saúde é extremamente importante, uma vez que existe pouca fonte de informação sobre este tema para os surdos, e mais trabalhos desses devem ser incentivados.

Palavras-chave: Biossegurança; Surdos; COVID-19.

\begin{abstract}
During the COVID pandemic, the use of technical biosafety terms used in the health field and in research laboratories has become much more frequent. However, many of these Portuguese terms do not yet exist in the Brazilian Sign Language - Libras, which hinders comprehension of the terms and brings risks to health of deaf people and makes communication with health professionals almost impeditive. Thus, the creation of a bilingual thesaurus (LibrasPortuguese) in the area of biosafety is essential. This research aims to present a bilingual manual with new terms in Libras, using videos, as a tool to allow communication and training for deaf and health professionals. Methodology: The selection of terms for the manual was based on media, newspapers and specialized literature using the descriptive systematic review method. 10 themes were selected for the elaboration of the manual's explanatory videos. Validation of the new words in Libras was carried out with a research group from INES (National Institute of Education for the Deaf). The videos were made available online at "Biocinais" platform. Result: We observed a high number of access to videos that explain the concepts of biosafety, PPE and CPE. Conclusion: The preliminary results demonstrate that
\end{abstract}


the construction of manuals that facilitate the understanding of deaf people about biosafety and their communication with health professionals is extremely important, since there is little source of information on this topic for the deaf, and more works like this should be encouraged.

Keywords: Biosafety; Deaf Community; COVID-19.

\section{Resumen}

Actualmente, con la pandemia del nuevo coronavirus, se tornó más frecuente el uso de términos técnicos de bioseguridad utilizados en el área de salud y en laboratorios de investigación. Pero muchos de estos términos utilizados en portugués todavía no existen en la Lengua Brasileña de Señales - LIBRAS, lo que genera su falta de comprensión, trae riesgos a la salud de los sordos y dificulta la comunicación con los profesionales del área. Así, se torna fundamental la preparación de materiales bilingües (LIBRAS-portugués) en el área de bioseguridad. El objetivo de esta investigación es presentar un manual bilingüe con nuevos términos en LIBRAS en formato de video para permitir la capacitación de los sordos y de los profesionales de salud. Metodología: seleccionamos los nuevos términos del manual con base en los medios de comunicación y la literatura especializada a partir del método de revisión sistemática descriptiva. Elegimos diez temas para la elaboración de los videos explicativos del manual. La validación de las nuevas palabras en LIBRAS fue realizada con un grupo de investigación del Instituto Nacional de Sordos. Los videos fueron divulgados en plataformas de Biociencias en Señales - Biocinais. Resultado: observamos un alto número de acceso a los videos que explican los conceptos de bioseguridad, EPI y EPC. Conclusión: los resultados preliminares demuestran que la construcción de manuales que faciliten el entendimiento de los sordos sobre la bioseguridad y su comunicación con los profesionales de la salud es importante, dado que existe poca información sobre este tema para los sordos, debiendo incentivarse más trabajos de este tipo.

Palabras clave: Bioseguridad; Sordos; COVID-19.

\section{Introdução}

Atualmente, estamos vivenciando o dia a dia da pandemia do novo coronavírus, SARS-CoV2; por isso, a imprensa escrita, falada e as redes sociais têm empregado termos técnicos de biossegurança no cotidiano. Quando se iniciou a veiculação, na mídia, de notícias sobre a pandemia, os profissionais da área da saúde começaram a falar sobre equipamentos de proteção individual (EPI) como luvas, máscaras, óculos e outros. Mas, observou-se que os termos técnicos utilizados em biossegurança empregados em comunicados oficiais causavam confusão e interpretações erradas em pessoas leigas e até mesmo nos profissionais de saúde, fossem eles surdos ou ouvintes. Além disso, vários conceitos como o de "risco", que significa a "chance ou probabilidade de pessoas se exporem ao perigo, acarretando prejuízo, lesão ou perda", acabam não sendo compreendidos no todo ou em parte, de acordo com o Centro de Prevenção e Controle de Doenças (CDC, 2009), o que pode resultar em dano físico ou químico.

Pode-se conceituar biossegurança como um conjunto de ações destinadas a prevenir, controlar, mitigar ou eliminar riscos inerentes às atividades que possam interferir ou comprometer a qualidade de vida, a saúde humana e o meio ambiente (Brasil, 2010b).

A biossegurança contribui para minimizar os riscos ocupacionais e procura intervir de forma positiva para que as pessoas trabalhem com segurança em locais considerados perigosos, que envolvam prejuízo e danos para sua integridade física e saúde. Porém, deve-se enfatizar que, mais do que ter um comprometimento institucional, é necessário que haja o envolvimento da instituição com a formação dos profissionais para que os espaços e práticas atendam aos requisitos necessários a fim de que riscos sejam minimizados. Isso exige uma atenção especial para os profissionais surdos e outros profissionais não surdos, de forma a facilitar a comunicação no ambiente de trabalho. Assim sendo, nada mais importante do que dispormos de uma ferramenta bilíngue sempre e, para isso, é necessário efetuar um bom treinamento do seu uso. Esta, sem dúvida, passa pelo acesso às informações necessárias para que os profissionais consigam exercer suas funções e seu papel de maneira eficaz sem prejudicar a si mesmos ou a seu ambiente de trabalho.

Assim sendo, para o profissional surdo, é indispensável que as instruções sejam dadas em sua língua natural, a Língua Brasileira de Sinais (Libras). Com isso, estão cumprindo a Lei 10.436/2002, conhecida como Lei de Libras (Brasil, 2002), e a empresa está demonstrando seu respeito pelo ser humano na figura de seus profissionais. Médicos e outros profissionais de 
saúde poderão, assim, ter o apoio desses profissionais que dominem a língua de sinais, visto que eles poderão atuar na função de mediadores ou tradutores de um paciente surdo com um médico que não domine a língua de sinais. No atual estágio da pandemia que vivemos, esta interlocução é fundamental para o esclarecimento e atendimento dos surdos que chegam aos hospitais.

A lei de Libras tem o mérito de reconhecer a Libras como meio legal de comunicação e expressão da comunidade surda e declara no seu parágrafo terceiro, que foi promulgada para fazer com que esses direitos sejam levados, de maneira integral, também às pessoas surdas. Cabe, portanto, ao Estado, através da implementação ou da fiscalização, garantir à população os direitos previstos em nossa Constituição e na Lei nº 10.436/2002.

Atualmente, com a expansão da internet e com a popularização de programas e recursos para criação, edição e compartilhamento de vídeos, é comum verificarmos a divulgação de inúmeros materiais, visando a necessidade de atualização no vocabulário especializado da Libras. Como exemplos desses materiais, têm-se: "Vocabulários de Física", do Projeto Sinalizando a Física (Bontan \& Br, 2014); "Glossário de Química" (Souza \& Silveira, 2011), assim como diversos vídeos compartilhados no YouTube, entre os quais os vídeos do Instituto Federal de Santa Catarina (IFSC, 2019).

Estudos anteriores (Cardoso, Botan \& Ferreira, 2010) revelam que há dificuldade em aplicar a Língua de Sinais para a produção de materiais bilíngues voltados a educandos surdos e ouvintes. Isso ocorre devido à falta de preparo e acesso às informações que esclareçam sobre a tradução de conceitos de material adaptado ou inclusivo.

O presente trabalho articula-se com o curso de extensão "Libras em Saúde: um estudo de sinonímia" do Departamento de Letras Clássicas e Vernáculas da Universidade Federal Fluminense coordenado pelo proponente deste artigo. O curso tem como foco a melhoria na qualidade do acesso à saúde por parte das pessoas surdas sinalizadores e pessoas com deficiência auditiva através da formação de profissionais da área. Os estudantes do curso são em sua maioria acadêmicos da enfermagem e profissionais da enfermagem, em especial, enfermeiros, auxiliares e técnicos da Fundação Municipal de Saúde de Niterói.

Dessa forma, este trabalho situa-se nas áreas da saúde e ensino e utiliza processos e estratégias bilíngues (Libras e português) presentes em laboratório e hospitais, que seguem as recomendações e normas de um Manual de Biossegurança, de acordo com as prescrições da Agência Nacional de Vigilância Sanitária (ANVISA), tendo como objetivo oferecer um guia confiável para formação dos profissionais envolvidos e para elaborar com segurança as tarefas necessárias.

Nesse contexto, considera-se que é necessário um estudo do Léxico da Libras, no registro de sinais terminológicos da Libras, o que consiste em aproveitar a expansão lexical que a língua vivencia com regras especificas sobre Biossegurança. Não temos a pretensão de atender a todas as áreas de conhecimento, mas sim de que este trabalho tenha como objetivo relatar uma experiência vivenciada por meio de pesquisa qualitativa sobre a produção de vídeos na área de enfermagem para o Manual de Biossegurança Bilíngue no ambiente acadêmico da Universidade Federal Fluminense - UFF.

\section{Metodologia}

Este é um estudo de revisão sistemática descritiva, desenvolvida com produção científica indexada nas seguintes bases eletrônicas de dados: Base de Dados de Enfermagem (BDENF), Base de dados da Literatura Latino-Americana e do Caribe em Ciências da Saúde (LILACS) e Biblioteca virtual da Fundação Oswaldo Cruz (FIOCRUZ). Esta pesquisa utilizou-se da ferramenta de busca existente no próprio portal no qual inserimos o descritor: Biossegurança em saúde.

Citaremos aqui a pesquisa de Castro (2001), que afirma que a revisão sistemática responde a uma pergunta específica e utiliza métodos explícitos e sistemáticos a fim de identificar, selecionar e avaliar criticamente os estudos, para a coleta e a precisão da análise dos dados levantados nos estudos que foram incluídos na revisão. De acordo com Pereira e Bachion (2006), outros critérios utilizados com testes de relevância são: A) recorte temporal abrange o período compreendido entre dezembro de 2019 a dezembro de 2020. B) foram selecionados artigos a partir da análise dos títulos/resumos/assuntos, neste caso artigos 
em Língua Portuguesa. C) após o levantamento dos dados, estes foram caracterizados por área de conhecimento e frequência de aparecimento. Assim, os critérios de exclusão foram: publicações que não estavam referendadas como artigos científicos e trabalhos de caráter internacional.

Foram utilizados no tratamento de dados da pesquisa a classificação por área temática, o que nos capacitou a ter uma visão panorâmica sobre pesquisas desenvolvidas na área de Ciências Biológicas e/ou Biologia com enfoque na Biossegurança e suas várias aplicações.

Sendo um estudo de natureza descritiva cujo tema aborda a experiência sobre a construção de um manual de biossegurança em forma de videoaulas em Libras, a seleção dos termos de biossegurança foi feita por docentes de Libras e especialistas em biossegurança e biotecnologia, que são os autores deste artigo. As bases de consulta dos termos foram notícias de jornais de ampla circulação, redes sociais e literatura especializada em biossegurança. Após a análise dessas fontes e ampla discussão com docentes de Libras e biossegurança, ficou estabelecido que as videoaulas abordariam os seguintes temas: utilização de equipamentos de proteção individual e coletiva, barreiras de contenção primária e secundária e termos usados pelos profissionais da área de saúde e biotecnologia. A validação dos novos sinais criados para expressar os termos técnicos selecionados foi realizada com membros do grupo de pesquisa do Instituto Nacional de Educação dos Surdos (INES) composto por surdos. Após a seleção dos temas, foi produzido um roteiro técnico, com os elementos de filmagem, tais como: posição, ângulo, fundo e uso de imagens em cada cena. Foram discutidas com os professores da área de Libras e especialistas em Ciências e Biotecnologia as adequações lexicais, culturais e sociolinguísticas. Dessa forma, para a produção das videoaulas, primeiramente criou-se uma espécie de sinopse da história, com o roteiro com cada cena em que ficou estabelecido o cenário, e as "falas" elencadas.

Foram desenvolvidos vídeos sinalizados em Libras com a presença de legendas, bem como textos escritos com registros dos conteúdos no próprio manual, seguindo Lebedeff e Santos (2014). Além disso, os vídeos foram elaborados por meio da utilização da ferramenta QR Code (Quick Response Codes ou Códigos de Resposta Rápida), promovendo, assim, uma boa acessibilidade, conforme Corrêa, Souza e Marçal (2012), na qual é possível visualizar os materiais através da técnica digital em imagem, ou seja, basta clicar na imagem da miniatura do vídeo para ser encaminhado diretamente ao hiperlink 1 da playlist do canal no YouTube2.

Segundo Corrêa, Souza e Marçal (2012), os QR Codes podem vincular o mundo físico ao virtual na gestão da comunicação ao permitir, por exemplo, que os estudantes unam informações com um objeto, um prédio histórico, ou algum lugar que permita seu uso.

Sobre os temas abordados no manual foram divididos em 10 capítulos, em 28 vídeos traduzidos do português para Libras, a saber:

- Capítulo 1: Biossegurança conceito I e II, de acordo com as instruções fornecidas pela Agência Nacional de Vigilância Sanitária (ANVISA) sobre condições de segurança para prevenir risco de acidentes;

- Capítulo 2: Diz respeito a Barreiras de contenção que envolvem termos sobre EPI e EPC;

- Capítulo 3: Trata do Risco, explicações sobre o conceito deste e seus tipos: I. riscos de acidente; II. riscos ergonômicos; III. riscos físicos; IV. riscos químicos;

- Capítulo 4: Perigo, apresenta-se o conceito em Biossegurança;

- Capítulo 5: EPI, contém algumas consideraç̃oes sobre o uso de equipamento de proteção individual e exemplos:

1 Sinônimo de link, que significa qualquer coisa que se coloca em uma página da web e que, quando clicada com o botão esquerdo do mouse, abre uma página diferente ou um lugar diferente na internet.

2 Disponível em: <https://www.youtube.com/watch?v=Pn3eN5KAMDE\&list=PL6eeHuR8hrreyRxbuQvqyk-

2D6gPkVQys\&index=2\&t=0s $>$. Acesso em 22 jun. 2020. 
capacete, óculos, máscaras, luvas e jaleco; apresentam-se ainda orientações sobre a ordem de colocar e sequência de retirada desses equipamentos;

- Capítulo 6: EPC, refere-se à importância do uso de equipamento de proteção coletiva, como, por exemplo: extintor, capela de exaustão, chuveiro de emergência e para lavar olhos, cabine de segurança biológicas (CSB), autoclave. Há neste capítulo algumas observações de segurança em caso de acidentes com substância química;

- Capítulo 7: Boas Práticas Laboratoriais, em que se apresentam recomendações a fim de diminuir riscos em ambiente laboratorial;

- Capítulo 8: Sinalização, divulgação de conhecimento para manuseio de materiais identificados com símbolos;

- Capítulo 9: Legislação, apresenta-se regulamentação sobre uso de EPI estabelecida pelas Normas Reguladoras NR6 e NR9;

- Capítulo 10: Condutas de Emergência, que se referem a primeiros socorros no caso de acidente.

As videoaulas foram disponibilizadas no formato digital através do $Q R$ Code, baixado gratuitamente do Portal Digital (BIOCINAIS, 2019) do Curso Biociências em sinais: Meio ambiente e saúde, ligado ao Programa de Pós-graduação em Ciências e Biotecnologia. Neste portal, foi possível quantificar o número de acesso de cada videoaula.

\section{Resultados e Discussão}

Articulando-se com o curso de extensão "Libras em Saúde" e seus cursistas, em sua maioria estudantes e profissionais da enfermagem, realizamos buscas em periódicos científicos da área na Biblioteca Virtual em Saúde (BVS) em enfermagem. Foram encontrados 959 estudos com os descritores Biossegurança em saúde, em todos os índices e em todas as fontes. Considerando-se apenas os estudos publicados nas Ciências da Saúde em geral, obtiveram-se 368 produções na LILACS, 164 na BDENF e 117 na FIOCRUZ, totalizando 649 estudos. Após teste de relevância A, foram selecionados 358 trabalhos que, com o teste de relevância B, resultou em 214 estudos (tabela 1).

O Teste de relevância é um instrumento que define e limita o tipo de pesquisa que vai ser útil para a Revisão Sistemática (RS) ou para a Metanálise (MA). Segundo os pesquisadores (Nagib, Aldemar, \& Castro, 1997), esse teste é primordial para as áreas de saúde pública, medicina e enfermagem. Ele é elaborado a partir de um questionário cujas respostas redundam em afirmativas ou negativas. As questões que são formuladas devem ser claras e objetivas segundo o pesquisador, sob pena das decisões tomadas serem obscuras.

Corroborando a premissa de Nagib, Aldemar e Castro, (1997) e Castro (1997), outro pesquisador, Counsell (1997) declara em seu trabalho que perguntas claras que não deixem margem a respostas ambíguas são vitais para se definir a estrutura da RS e MA. Dessa forma, será possível aos leitores utilizá-las como guias ou parâmetros que comprovem a importância do tema que está sendo tratado.

O teste de relevância é, portanto, um teste que visa uma análise criteriosa dos resumos com vistas a identificar se estes abordavam, de algum modo, elementos suficientes para alguma análise conceitual pretendida. Essa triagem possibilitou a exclusão de artigos que não se enquadrem nos critérios pretendidos, por tratarem de outros conceitos relacionados àquele de interesse do estudo. Vejamos Tabela 1, sobre Número de estudos selecionados por Teste de Relevância, utilizando os descritores: biossegurança em saúde. 
Tabela 1 - Coleta e apuração de artigos a partir dos filtros mais relevantes.

\begin{tabular}{|c|c|c|c|}
\hline \multirow[t]{2}{*}{ FONTE DE BUSCA } & $\begin{array}{l}\text { PRIMEIRO } \\
\text { FILTRO: }\end{array}$ & $\begin{array}{l}\text { SEGUNDO } \\
\text { FILTRO: }\end{array}$ & $\begin{array}{l}\text { TERCEIRO } \\
\text { FILTRO: }\end{array}$ \\
\hline & BIOSSEGURANÇA & SURDOS & LABORATÓRIOS \\
\hline LILACS & 368 & 214 & 107 \\
\hline BDENF & 164 & 108 & 94 \\
\hline FIOCRUZ & 117 & 36 & 13 \\
\hline $\begin{array}{c}\text { TOTAL } \\
\text { ARTIGOS }\end{array}$ & 649 & 358 & 214 \\
\hline COLETADOS & & & \\
\hline
\end{tabular}

Fonte: Autores (2021).

Desse total, elaborou-se uma listagem única, na qual foram excluídos 48 artigos por estarem repetidos nas bases de dados utilizadas, restando 148 estudos que seguiram para teste de relevância C. Nesse último teste, realizou-se a leitura integral dos estudos, sendo selecionadas 15 referências para análise. A Tabela 2, mostra os motivos de exclusão dos 133 artigos.

Tabela 2 - Justificativas para exclusão dos artigos no teste de relevância C.

\begin{tabular}{|c|c|c|}
\hline Motivo Geral & Motivo Específico & Quantidade \\
\hline \multirow{3}{*}{$\begin{array}{l}\text { Não abordavam } \\
\text { Biossegurança como } \\
\text { todo. }\end{array}$} & $\begin{array}{l}\text { Formação/capacitação do } \\
\text { enfermeiro }\end{array}$ & 26 \\
\hline & Bioética & 05 \\
\hline & Saúde/segurança do trabalhador & 18 \\
\hline & Acidente & 22 \\
\hline & Atenção à saúde & 08 \\
\hline & Educação em saúde & 03 \\
\hline & Educação em Biossegurança & 04 \\
\hline & Elaboração de material didático & 03 \\
\hline & Materiais biológicos & 04 \\
\hline & Riscos & 40 \\
\hline $\begin{array}{l}\text { TOTAL DE ARTIGOS } \\
\text { EXCLUÍDOS: }\end{array}$ & & 133 \\
\hline
\end{tabular}

Percebe-se que 133 dos estudos foram excluídos por não abordarem o tema "Biossegurança". Dentre estes os que abordaram a temática "riscos e acidentes" somam juntos 62 trabalhos.

Em relação à fonte de publicação, os 15 artigos selecionados (Quadro 01) foram encontrados em 11 periódicos diferentes, dos quais 04 periódicos eram específicos da enfermagem. 
Quadro 1 - Artigos estudados por temática específica em Biossegurança.

\begin{tabular}{|l|c|}
\hline Estudo & Ano \\
\hline $\begin{array}{l}\text { Biossegurança e a enfermagem nos cuidados clínicos: contribuições para a saúde do } \\
\text { trabalhador }\end{array}$ & 2010 \\
\hline Biossegurança: Conhecimento e Adesão às Medidas de Precauções Padrão num Hospital & 2011 \\
\hline A biossegurança e segurança do paciente na visão de acadêmicos de enfermagem & 2012 \\
\hline A biossegurança sob o olhar de enfermeiros & 2012 \\
\hline $\begin{array}{l}\text { Biossegurança: conhecimento e adesão pelos profissionais do corpo de bombeiros militar } \\
\text { de Minas Gerais }\end{array}$ & 2013 \\
\hline Biossegurança na central de quimioterapia: o enfermeiro frente ao risco químico & 2014 \\
\hline $\begin{array}{l}\text { Biosseguranca na perspectiva da equipe de enfermagem de Unidades de Tratamento } \\
\text { Intensivo }\end{array}$ & 2014 \\
\hline Inovação tecnológica e as questões reflexivas do campo da biossegurança & 2014 \\
\hline Biossegurança e resíduos de serviços de saúde no cotidiano acadêmico & 2014 \\
\hline $\begin{array}{l}\text { Concepções de Biossegurança de Docentes do ensino Técnico de Enfermagem em um } \\
\text { Estado do Sul do Brasil }\end{array}$ & 2015 \\
\hline Biossegurança no centro de materiais e esterilização: dúvidas dos profissionais & 2016 \\
\hline Biossegurança sob a ótica dos graduandos de enfermagem & 2017 \\
\hline $\begin{array}{l}\text { Biossegurança em serviço de embelezamento: conhecimento e práticas em uma capital } \\
\text { do nordeste brasileiro }\end{array}$ & 2017 \\
\hline Conhecimentos e condutas de biossegurança entre docentes de enfermagem & 2017 \\
\hline Biossegurança em salões de beleza: avaliação da estrutura e dispositivos & 2018 \\
\hline
\end{tabular}

Fonte: Autores (2021).

A avaliação dos artigos seguiu as seguintes etapas (Pereira \& Bachion, 2006):

Figura 1 - Etapas de avaliação dos artigos.

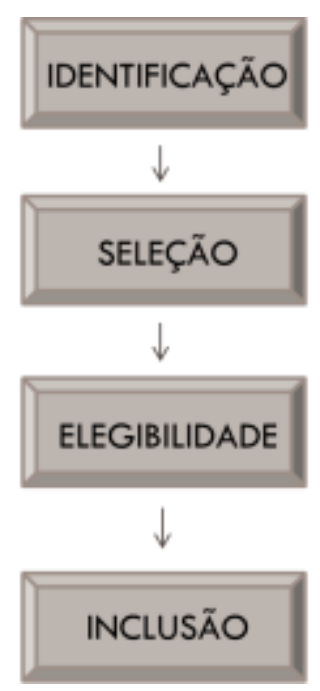

Escolha dos termos de biossegurança relevantes para os artigos as serem analisados.

Uso dos filtros para apurar os materiais de maneira qualitativa.

Motivos para permanência ou exclusão dos estudos selecionados.

Triagem final de artigos de biossegurança incorporada a área da Saúde.

Fonte: Autores (2021). 
Logo após, foi realizada uma busca por fontes de dados para verificação de sinais existentes de termos utilizados disponibilizados em dicionários, web, sites, glossários, sendo (6) fontes de registros de sinais totalizando uma lista de termos aplicados para a construção do manual considerando os aspectos linguísticos da Libras na proposta de criação dos sinais e aspectos conceituais dos termos.

Quadro 2 - Quanto à presença dos termos selecionados nos dicionários e glossários mencionados.

\begin{tabular}{|c|c|c|c|c|c|c|}
\hline & Spread & INES & Capovilla & IFSC & EPEEM & CAS FCEE \\
\hline Acidente & Não & Sim & Sim & Não & Não & Não \\
\hline Álcool & Sim & Sim & Sim & Não & Não & Não \\
\hline Bioética & Não & Não & Não & Não & Não & Não \\
\hline Biossegurança & Não & Não & Não & Não & Não & Não \\
\hline Capacete & Não & Sim & Sim & Não & Não & Não \\
\hline Epidemia & Sim & Sim & Sim & Não & Sim & Não \\
\hline Extintor de Incêndio & Sim & Não & Sim & Não & Não & Não \\
\hline Jaleco & Sim & Não & Não & Não & Não & Não \\
\hline Laborató-rio & Sim & Sim & Sim & Não & Não & Não \\
\hline Luva & Sim & Sim & Sim & Não & Não & Não \\
\hline Máscara de Proteção & Sim & Não & Não & Não & Não & Não \\
\hline Óculos de Proteção & Não & Não & Não & Não & Não & Não \\
\hline Pandemia & Não & Não & Não & Não & Não & Não \\
\hline Perigo & Não & Sim & Sim & Não & Não & Não \\
\hline Risco & Não & Não & Não & Não & Não & Não \\
\hline
\end{tabular}

Fonte: Autores (2021).

\subsection{O Manual de Biossegurança}

Após verificação de sinais existentes de termos utilizados disponibilizados em dicionários, web, sites, glossários prosseguiu-se a elaboração do manual através da produção das videoaulas abordando os seguintes temas: utilização de equipamentos de proteção individual e coletiva, barreiras de contenção primária e secundária e termos usados pelos profissionais da área de saúde e biotecnologia.

O manual com diversos termos novos de biossegurança em Libras foi disponibilizado através do QR Code para facilitar os profissionais de saúde a se comunicarem com os surdos e explicarem como eles devem se proteger dos riscos e perigos, através de procedimentos de contenção primária e secundária, conforme Gráfico 1. 
Gráfico 1 - Número de acessos de cada termo e conceito de biossegurança antes e após o início da pandemia.

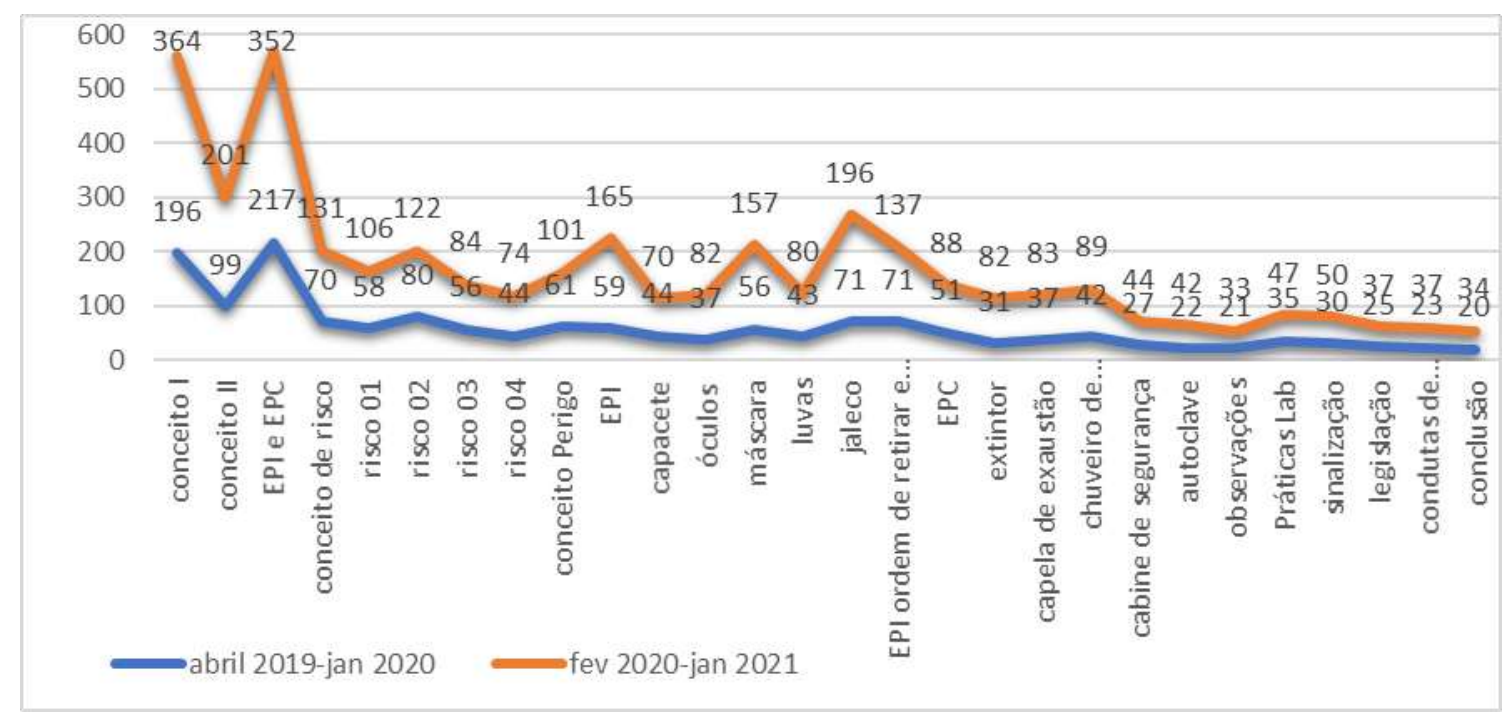

Fonte: Autores (2021).

Os membros que fazem parte da equipe de estudo e pesquisa do INES concluíram que, embora existam atualmente algumas iniciativas na área, o número de sinais continua ainda sendo incipiente para as necessidades imediatas da comunidade surda bem como dos profissionais de saúde envolvidos com essa comunidade.

O manual de Biossegurança publicado no portal Biociências em sinais (Biocinais, 2019) plataforma com origem de tráfego em diversos canais da internet teve 3,2\% do material baixado sobre Biossegurança, sendo 55,2\% de tráfego direto no “Portal Biocinais", dos quais representam 9,4\% em nível de alcance dos materiais acessados neste portal. No gráfico 1, pode-se observar o número de acessos de cada termo e conceito de biossegurança.

A análise do número de acessos aos 28 vídeos apontam que entre 01 de abril de 2019 a 31 de janeiro de 2020, os conceitos sobre Biossegurança, EPI, EPC e uso de máscara foram os mais acessados, o que representa cerca de $44 \%$ de visualizações de conceitos por vídeos em relação ao total $(\mathrm{N}=1626)$ e que entre 01 fevereiro a 20 de janeiro de 2021 , houve aumento de $55 \%$ nas buscas sobre esses temas ( $=3088)$, após o momento em que o Ministério da Saúde confirmou o primeiro caso do novo coronavírus no Brasil (03 de fevereiro de 2020). É importante ressaltar que os vídeos foram publicados simultaneamente, no final de março de 2019, sem divulgação em grande escala.

A comparação do número de vídeos bilíngues que tratam do tema biossegurança que foram visualizados pelo público interessado no período de 10 meses antes da pandemia - abril de 2019 a janeiro de 2020 - e após o início da pandemia fevereiro a janeiro de 2021- pode ser observada no gráfico 1. É importante ressaltar que o número de acesso a esses vídeos no curto período (10 meses) após o início da pandemia cresceu e foi superior ao número de acessos realizados nos 10 meses que antecederam a pandemia. Este fato demonstra a importância do tema de biossegurança apresentado de forma bilíngue e principalmente a sua real necessidade nesse período de crise que o mundo está passando.

A base da biossegurança leva em conta dois tipos de contenção, a primária e a secundária. Ambas são aplicadas em escolas, laboratórios, consultórios e hospitais. Pode-se, portanto, declarar que a contenção primária está ligada ao uso de equipamentos de proteção individual, tais como luvas, máscaras, protetor facial, óculos de proteção, aventais, jalecos entre outros. Esses equipamentos têm como função principal proteger a pessoa que está trabalhando no laboratório ou no atendimento público no serviço de saúde. Vamos destacar neste contexto os tipos de máscaras, uma vez que, atualmente, o uso delas é recomendado para todas as pessoas e não apenas aquelas com suspeita de infecção pelo coronavírus ou profissionais de 
saúde. Existem vários tipos de máscaras de proteção, porém vamos destacar apenas os dois modelos mais em evidência: a cirúrgica e a N95.

Com relação ao uso de máscaras, é frequente que os profissionais das áreas que delas necessitam utilizem mais comumente a máscara cirúrgica, porém, aquela considerada ideal atualmente para impedir que esses profissionais se contaminem é a N95 ou PFF2. Sabe-se que a diferença entre a N95 e a máscara cirúrgica está na capacidade de filtragem de partículas e no modo como retém as mesmas. A máscara cirúrgica é uma via de mão única, retendo apenas o que é emitido por quem a está utilizando. Se o usuário apresenta sintomas de gripe ou resfriado, ela apenas evita que ele a propague.

Já a máscara N95 garante a proteção nos dois sentidos por possuir um filtro de ar. Esse filtro é responsável pelo bloqueio de $95 \%$ de todas as partículas em suspensão presentes no ambiente, além de garantir a proteção contra as doenças cuja natureza de transmissão se dá por via aérea como é o caso do coronavírus.

O governo da Alemanha acaba de anunciar uma nova norma na noite do dia 19 de janeiro de 2021, notícia que foi veiculada nos principais jornais do país e diferentes noticiários pelo mundo: todos os cidadãos deverão usar máscaras N95 ou KN95 e máscaras cirúrgicas. A norma foi baixada sob a forma de lei, com validade a partir do dia 25 de fevereiro de 2021. Desta forma, todos os alemães deverão seguir essa recomendação. Segundo consta na notícia, a França e a Áustria também avisaram seus cidadãos que as máscaras de pano deixaram de ser as mais indicadas e recomendaram o uso da N95. O motivo, segundo eles, é que esta oferece uma proteção melhor em relação ao coronavírus, o que é importante principalmente nesse momento em que, por causa da mutação, o vírus se tornou mais contagioso (UOL, 2021).

$\mathrm{O}$ segundo tipo de contenção, a contenção secundária, diz respeito às instalações dos laboratórios e hospitais. As construções de suas instalações devem ser meticulosamente planejadas a fim de serem de fato efetivas na proteção de sua equipe de trabalho e de sua comunidade. Com isso, elas serão garantia contra agentes infeciosos que porventura acidentalmente sejam liberados desses locais.

Müller e Mastroeni (2004), em um estudo sobre tendências de acidentes de trabalho em laboratórios de pesquisa, apontam que o conceito de risco sofre alterações ao longo dos anos, que risco se relaciona com acidente. Assim, para minimizar os riscos e, consequentemente, evitar acidentes de trabalho, devem-se desenvolver estratégias e procedimentos adequados, tais como: implementações de normas especificas para manter o ambiente seguro.

O gráfico 02 destaca os vídeos mais acessados no portal Biocinais. Nele pode ser constado que os conceitos de biossegurança e os temas sobre proteção individual (EPI) e coletiva (EPC,) através dos procedimentos corretos do uso de luvas e máscaras, foram os mais acessados. Segue, gráfico comparativo do número de acessos dos vídeos bilíngues, no portal Biocinais, no período anterior à pandemia (de abril de 2019 a janeiro de 2020) e após o início dela (de fevereiro 2020 a janeiro de 2021). 
Gráfico 2 - Temas dos vídeos bilíngues mais acessados no Portal Biocinais antes e após o início da pandemia.

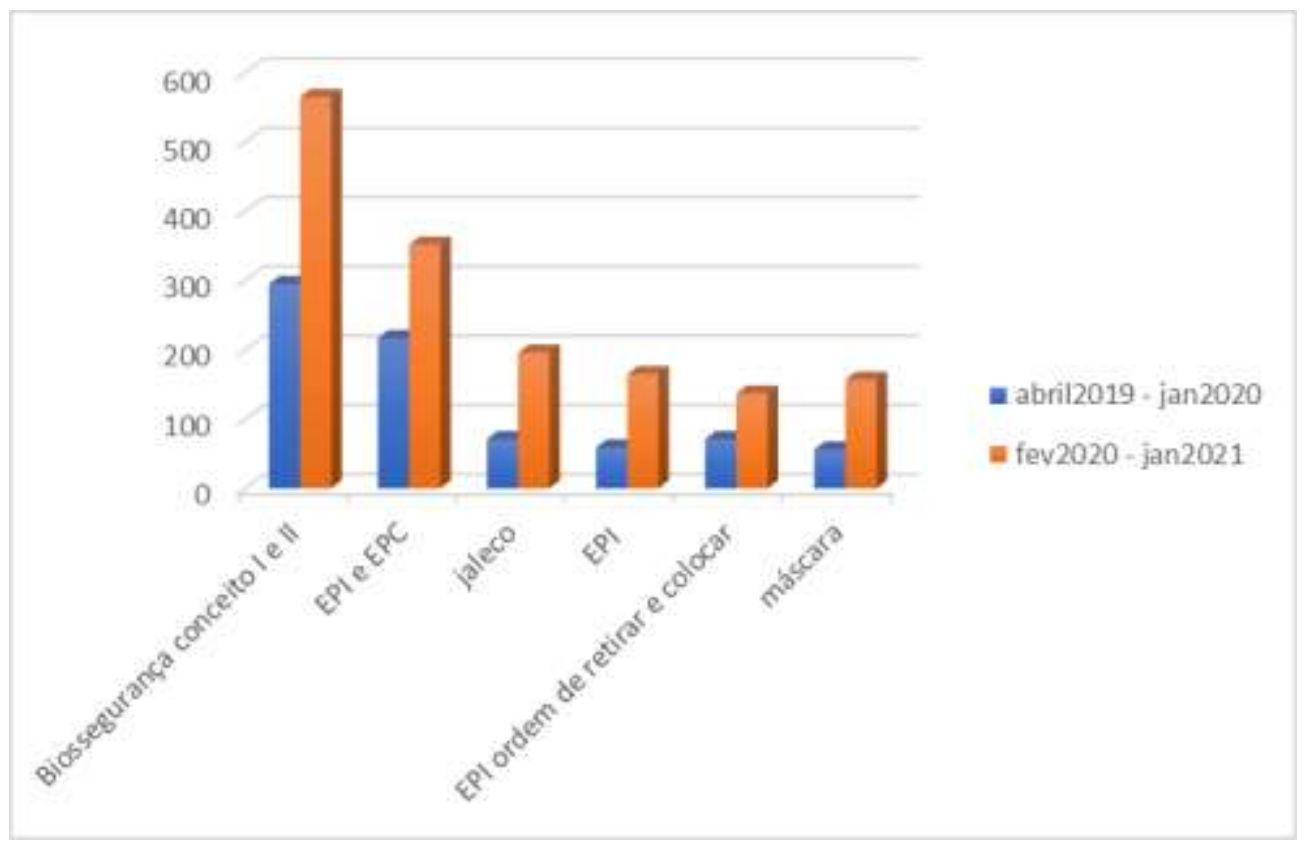

Fonte: Autores (2021).

O número de acessos aos vídeos apresentados no gráfico indica o interesse da comunidade surda, de professores de Ciências e Biologia, tradutores e intérpretes de Libras e docentes de Libras nas boas práticas de biossegurança em laboratórios e que necessitam de termos específicos (Souza \& Silveira, 2011) para trabalhar este vocabulário com professores das escolas e universidades.

As necessidades de obtenção de informações para a comunidade surda para a correta utilização e aproveitamento das diretrizes e normas do Manual de Biossegurança exigem que seja necessária a utilização da Libras, sua língua materna. Assim sendo, é imperativo que sejam criados termos específicos da área da saúde, destacando-se alguns importantes termos de uso frequente, tais como: Biossegurança, Risco, Máscara de Proteção, Perigo, Bioética, Óculos de Proteção, Pandemia, Jaleco.

Os termos citados não possuíam seus correspondentes em Libras até a produção deste manual. Um trabalho de estudo e pesquisa elaborado pelos membros do grupo de pesquisa que fazem parte da equipe responsável pelo estudo, implantação e criação de novos sinais do Instituto Nacional de Educação de Surdos (INES). Considerando-se a extrema importância do projeto de criação do Manual de Biossegurança, essa equipe tomou a si a iniciativa de divulgar e registrar os sinais específicos da área de Biossegurança ao mesmo tempo em que ressaltou a necessidade de reunir a comunidade surda como também os profissionais de saúde a fim de apresentar sua proposta de sinais adequados visualmente à imagem, conceito e imagem do emprego do termo.

Observaram-se na elaboração deste material as dificuldades para a produção de novos sinais de acordo com seus respectivos conceitos, como, por exemplo, os sinais de RISCO e PERIGO, pois se apresentam nas traduções em geral como idênticos apesar de não serem; por isso, foi necessário criar uma estratégia contextualizada, uma vez que a palavra "risco", em biossegurança, está associada à exposição ao perigo (Brasil, 2010a) e, neste caso, não deve ser representada pelo mesmo sinal em Libras, a fim de evitar equívocos em conceitos e/ou o cruzamento lexical decorrente de termos que apresentam a mesma matriz lexical.

Esses aspectos vêm sendo abordados e discutidos em escassos estudos recentes (Barral, Pinto-Silva, \& Rumjanek, 2012), os quais ressaltam a necessidade de se pensarem estratégias e recursos inovadores para o ensino de Ciências para alunos 
surdos, nas classes inclusivas ou não, além da criação e difusão de novos sinais científicos que contemplem e respeitem toda a especificidade e necessidade desses estudantes.

De acordo com Lebedeff e Santos (2014), há necessidade de produção de vídeos sinalizados devido à escassez desse tipo de recurso com potencial pedagógico e direcionamento dos conhecimentos que se constituem em Libras para o cotidiano.

O manual também tem outra importante finalidade que deve ser destacada. Por meio dele é possível a formação adequada nas áreas de saúde e biossegurança dos profissionais de saúde surdos.

A construção do manual estimulou nosso grupo de pesquisa a investir na produção de aplicativos (Nilo, Militão, \& Bourguignon, 2019), glossários (Francisco, Militão, Campello, \& Bourguignon, 2019), cursos presenciais (BIOCINAIS, 2019) e cursos on-line (EDUCAPES, 2019) voltados para a formação de professores e para a comunidade surda que trabalha em laboratórios, principalmente na Fiocruz, Instituto Vital Brasil e UFF.

Sabemos que, em termos de recursos didáticos, os experimentos e aqueles que se baseiam na exploração de elementos visuais (vídeos, animações, simulações dentre outros) se apresentam como relevantes no processo de apreensão das informações e aprendizagem dos surdos leigos ou profissionais da área. Observou-se que o material proposto constitui um recurso efetivo para o ensino dos conceitos em Biossegurança e para a multiplicação das informações relativas ao tema. Como a Libras é uma língua visual-espacial que usa da espacialidade para sua produção e recepção, é necessário que os materiais didáticos atentem para as especificidades lexicais da língua.

As Línguas de Sinais são línguas com canais de recepção e produção diferentes das línguas orais. Enquanto nas línguas orais esses canais são os ouvidos e o aparelho fonoarticulatório, nas de sinais são os olhos e as mãos. No Brasil, os surdos utilizam a Língua Brasileira de Sinais, a Libras. A oficialização dessa língua, através da Lei 10.436/02 e, posteriormente, com o Decreto 5.626/05 (Brasil, 2005), promoveu a disseminação do seu ensino e do seu estudo. Além disso, o Decreto ${ }^{\circ} 5.626$ tornou o ensino da disciplina de Libras obrigatório nos cursos de licenciatura e fonoaudiologia, cujo objetivo era inserir na formação de professores conhecimentos linguísticos da Libras e aspectos teóricos sobre a educação de surdos.

Segundo pesquisadores (Carvalho Silva \& Guimarães Faria, 2016), o fortalecimento da identidade e cultura surda se dar devido as contribuições de diálogos na apropriação da tecnologia visual. Os vídeos, quando destinados para os surdos, precisam ser caracterizados pela capacidade de atrair a atenção desses sujeitos, com seus componentes lúdicos agregados e potencialidades que este recurso oferece. Além disso, sendo a Libras, que vai ser apresentada nesses vídeos com ajuda de intérpretes ou figuras de desenho animado, uma língua visual-espacial, ela apresenta peculiaridades específicas distintas das línguas orais. Por exemplo, um dos componentes fonológicos da Libras é o movimento e, infelizmente, a maioria das cartilhas existentes que examinamos em diversos cursos não possibilita a visualização do movimento.

Muitos materiais utilizam a tática de desenhar setas para indicar direção e pontilhados para informar movimento. Entretanto, não são informações claras e precisas. Além disso, no cenário da Libras, tem-se a cultura surda e seus artefatos, que muitas vezes são desconhecidos pela maior parte dos estudantes da disciplina de Libras, disciplina esta que se tornou obrigatória em cursos de Licenciatura nas universidades. Observamos que a maioria dos alunos universitários que frequenta o curso conhece o surdo e sua língua a partir das considerações do senso comum, não possuindo saberes sobre as causas do sujeito surdo e a sua cultura e como consequência sobre as Línguas de Sinais (LS) e a Libras (Língua Brasileira de Sinais).

É possível perceber que esses estudantes enfrentam grandes dificuldades em aprender uma língua com a qual têm contato apenas uma ou duas vezes por semana, como ocorre na disciplina de Libras. A Língua de Sinais é uma segunda língua para os alunos ouvintes, que têm como primeira língua a Língua Portuguesa. O contato com a Libras ocorre somente nas aulas, com poucas interações linguísticas convivência com outros surdos ou pessoas fluentes em Libras no ambiente fora da universidade. Tendo em vista esse contexto, faz-se necessário que professores de Libras desenvolvam vídeos de curta- 
metragem que possibilitem a aprendizagem dessa língua de sinais numa perspectiva comunicativa, fugindo da limitação imposta pelas "cartilhas".

O vídeo é uma ferramenta que pode ser inserida para ensino e divulgação de forma eficiente, pois solicita do receptor uma atitude de compreensão, imaginação, possibilitando o uso da percepção visual, lógica, emoção, razão, entre outros. Dessa forma, (Moraes \& Torres, 2004), explicam que a adoção de vídeos na práxis docente é um instrumento significativo, apresentando-se como ferramenta rica em sua estruturação, na medida em que permite o uso de textos como legendas, imagens e direciona a produção do conhecimento.

Para Campello (2020), com a ajuda dos vídeos, o surdo pode livremente explorar a linguagem gesto-visual; o imaginário com eles é estimulado em busca da compreensão de conceitos. Sendo assim, os materiais midiáticos acabam por trabalhar a parte visual, o que resulta numa grande contribuição para a comunidade surda quando empregados de forma correta e associados com questões ligadas a temas, como a saúde, propiciando informações relevantes para os profissionais que trabalham na área de Biossegurança ou qualquer outra temática.

No entanto, apesar de reconhecer a importância da utilização de vídeos, tanto para o ensino de Biossegurança no meio acadêmico das universidades quanto para a disseminação de conceitos e metodologias que sejam compatíveis à elaboração de um manual de Biossegurança bilíngue visando a auxiliar profissionais surdos e ouvintes a assimilarem bem e com eficácia esses conceitos, observamos uma carência no preparo dos professores universitários, bem como na aquisição de aplicativos, laboratórios e instrumentos tecnológicos indispensáveis para a produção e distribuição desses vídeos. De nada adianta reconhecermos que esse artefato tecnológico é de suma importância e os estudantes e profissionais surdos confirmarem a sua necessidade se não tivermos condições e meios de criá-los, implantá-los e difundi-los.

Os docentes, ao utilizarem seus vídeos em práticas dentro de suas salas de aula, necessitam estar familiarizados com esta ferramenta através de uma formação que os possibilite alcançar a proficiência na sua utilização. O pesquisador Mercado (2009) elenca as seguintes habilidades que esses profissionais devem possuir para alcançarem tal intento: boa formação, conhecimentos sólidos em didática e conteúdos relacionados, desenvolvimento de práticas pedagógicas voltadas para a educação online e as TIC (Tecnologias da Informação e Comunicação) e a correta utilização de ferramentas que proporcionem o atendimento das necessidades tanto individuais quanto coletivas. De posse dessas habilidades, o pesquisador declara que esses profissionais estarão, portanto, aptos a estimularem o espírito crítico, a capacidade de reflexão e o favorecimento da capacidade intelectual e afetiva. De posse do domínio desse conjunto de habilidades, os docentes se tornam capazes de se tornarem sujeitos autônomos e exercerem uma democracia participativa e responsável.

No entanto, a formação inicial ainda se apresenta carente nesses quesitos. Nos cursos brasileiros, um caminho viável para a superação dessa carência se encontra, na acepção de Mercado (2009, p.17), no fornecimento de cursos de formação continuada que proporcionem o contato dos docentes com as Tecnologias Digitais (TD), com isso, possibilitando a eles tornarem-se hábeis em seu manejo e concomitantemente ampliando seu desenvolvimento intelectual.

É necessário acrescentar a contribuição das pesquisas de Oliveira e Junior (2011) ao analisar as declarações fornecidas por docentes que constataram as vantagens do uso dos recursos midiáticos, especialmente de vídeos. Elas destacaram que uma das vantagens da utilização de tais recursos se refere ao fato de que os discentes possam assistir várias vezes ao mesmo trecho de um vídeo que não tenham compreendido, lançando mão, ainda, de várias funções disponíveis no controle remoto tais como: aumento do áudio, retrocesso e controle de pausa da imagem.

As formações continuadas de docentes, convém ressaltar aqui, têm grande proveito ao ocorrerem em grupos, para que haja uma reflexão com outros docentes, propiciando, assim, um compartilhamento de conhecimentos e experiências de sala de aula e contribuindo para o "desenvolvimento da criatividade e da autonomia dos professores", conforme declararam os pesquisadores Viégas e Rehfledt (2017, p. 52) em seus levantamentos. 
Convém destacar na atualidade a importância do uso do vídeo na vida dos discentes universitários. Muitos desses possuem canais no YouTube ou produzem um vídeo para ser colocado no Facebook, ou ainda realizam vídeo-gravações para serem enviadas pelo WhatsApp. São tecnologias que já fazem parte do cotidiano dos estudantes; portanto, cabe aos docentes se apropriarem da funcionalidade desse artefato para atingirem seus objetivos pedagógicos e educacionais. Reforçamos que o vídeo é mais um arsenal tecnológico que o docente dispõe para realizar o processo de ensino e aprendizagem. Para isso, é preciso incentivar a participação de outros docentes em cursos de formação continuada voltados para o uso das Tecnologias Digitais. Além disso, espera-se que tal formação oportunize a eles um pensar, relacionar e elaborar atividades que são de seu interesse ou estejam vinculadas aos seus materiais de aula.

De mais a mais, há um denominador comum na declaração de grande parte dos discentes universitários, ainda mais reforçado pelas exigências dos tempos de pandemia que eles vivem: todos são unânimes em declarar a importância atual da exibição, produção e apresentação de vídeos em canais como o Youtube, Facebook ou Whatsapp como forma de ampliar o acesso ao conhecimento, lançando mão dos diferentes recursos presentes de interatividade, feedbacks, replays, entre outros.

\section{Considerações Finais}

O impacto da utilização do manual de biossegurança apontado pelo número de acessos no "Portal Biocinais" em curto período de tempo demonstra que os objetivos propostos foram alcançados de modo positivo, pois ele aborda conceitos necessários para o entendimento da pandemia do novo coronavírus de maneira gratuita e com acesso aberto bilíngue (Português e Libras), proporcionando à comunidade surda um material em igualdade de direitos humanos no que se refere à divulgação científica e ao compartilhamento de conhecimento de qualidade que foca conceitos de EPI, EPC e normas de biossegurança. Dessa forma, este manual está contribuindo de modo significativo para a divulgação necessária para a prevenção de doenças e acidentes com agentes químicos, físicos e biológicos.

Espera-se que a proposta do manual possa contribuir e auxiliar em ambientes laboratoriais de escolas e universidades e no cotidiano de nossas vidas, uma vez que os termos de biossegurança estão sendo utilizados naturalmente com a chegada da pandemia do novo Coronavírus. Esses recursos estão disponíveis no youtube $e^{3}$ para serem utilizados por todos que se interessem, principalmente para o ensino de ciências e biossegurança, uma vez que a produção apresenta uma sequência didática, contextualizada aos parâmetros de Libras, para que esses conteúdos sejam trabalhados de forma mais específica na educação de surdos, tanto em nível de ensino médio quanto em nível de graduação.

Consideramos que o ensino de Libras possui especificidades de uma língua visual, com características próprias, que facilita a aprendizagem dos alunos surdos. Dessa forma, são necessários mais investimentos e planejamentos de estratégias de ensino-aprendizagem para favorecer o ensino de conceitos científicos. Portanto, a divulgação do conhecimento contido no Manual de Biossegurança contribuirá para o êxito do ensino e aplicação dos seus conceitos e normas para a comunidade surda. Assim, o conhecimento obtido para produção deste material nos conduz a outros estudos para trabalhos futuros como a produção de um glossário sobre Covid-19 e Biossegurança. Concomitantemente, faz-se necessário também equipar as universidades, destinando parte do seu orçamento para a aquisição de aplicativos, laboratórios e instrumentos tecnológicos indispensáveis para a produção e distribuição de vídeos, principal razão deste artigo.

\section{Referências}

ANVISA, A. N. de V. Sanitária. B. (2005). Informes Técnicos Institucionais Technical Institutional Reports. \& Rev Saúde Pública, 39(6), 989-991. https://www.scielo.br/pdf/rsp/v39n6/26998.pdf

\footnotetext{
${ }^{3}$ https://www.youtube.com/watch?v=Pn3eN5KAMDE
} 
Barral, J., Pinto-Silva, F. E., \& Rumjanek, V. M. (2012). Comunicando ciência com as mãos. https://cienciahoje.org.br/artigo/comunicando-ciencia-com-asmaos/

Biocinais. (2019). Biociências em Sinais. Portal digital do Curso Biociências em sinais: Meio ambiente e saúde website: http://biocinais.uff.br

Botan, E., \& Br], E. (2014). Ensino de Física para surdos: Três Estudos de Casos da Implementação de uma Ferramenta Didática para o ensino de Cinemática. Physics Teaching for the Deaf: Three Case Studies About the Implementation of a Teaching Tool for Teaching of Kinematics. https://if.ufmt.br/eenci/artigos/Artigo_ID229/v9_n1_a2014.pdf

Brasil, Lei 10.436, (2002). Dispõe sobre a Língua Brasileira de Sinais - Libras e dá outras providências. Diário Oficial República Federativa do Brasil, Brasília, DF, 24 abr. 2002. http://www.planalto.gov.br/ccivil_03/leis/2002/110436.htm>

Brasil, Decreto 5626, (2005). Regulamenta a Lei no 10.436, de 24 de abril de 2002, que dispõe sobre a Língua Brasileira de Sinais - Libras, e o art. 18 da Lei no 10.098, de 19 de dezembro de 2000. http://www.planalto.gov.br/ccivil_03/_ato2004-2006/2005/decreto/d5626.htm

Brasil. (2010a). Ministério da Saúde. Retrieved July 2, 2021, from Agência Nacional de Vigilância Sanitária - Anvisa website: http://portal.anvisa.gov.br/documents/4048533/4992156/Biosseguran\%C3\%A7a+e+Gerenciamento+de+residuos.pdf/b8bb3a6c-89ed-4b32-8b8b$235 \mathrm{f} 2 \mathrm{~b} 7651 \mathrm{bf}$

Brasil, Ministério da Saúde (2010b), Portaria n 3.204. Aprova Norma Técnica de Biossegurança para Laboratórios de Saúde Pública. Brasília. bvsms.saude.gov.br website: https://bvsms.saude.gov.br/bvs/saudelegis/gm/2010/prt3204_20_10_2010.html

Campello, A. R. de S. (2020). Pedagogia Visual na Educação dos Surdos-mudos. Revista Espaço, 0(52). https://doi.org/10.20395/re.v0i52.622

Cardoso, F. C., Botan, E., \& Ferreira, M. R. (2010). Sinalizando a Física - Vocabulários de Física. https://sites.google.com/site/sinalizandoafisic a/vocabularios-de-fisica

Carvalho Silva, D., \& Guimarães Faria, N. (2016). Legendas e Janelas: Questões e Acessibilidade. Revista Sinalizar, 1(1), 65. https://doi.org/10.5216/rs.v1i1.36156

Castro, A. A. (2001). Revisão sistemática com e sem metanálise. Evidencias.com website: http://www.evidencias.com

CDC, C. for D. control and P. (2009). Biosafety in Microbiological and Biomedical Laboratories 5th Edition. https://www.cdc.gov/labs/pdf/CDCBiosafetyMicrobiologicalBiomedicalLaboratories-2009-P.PDF

Corrêa, M. I. de S., Souza, A. C. R. de, \& Marçal, M. C. C. (2012). O uso do Qr Code na gestão da comunicação: o caso da rede social WineTag. Informe: Estudos Em Biblioteconomia E Gestão Da Informação, 1(1), 118-132. https://periodicos.ufpe.br/revistas/INF/article/view/48

Counsell, C. (1997). Formulating questions and locating primary studies for inclusion in systematic reviews. https://citeseerx.ist.psu.edu/viewdoc/download?doi=10.1.1.685.4455\&rep=rep1\&type=pdf

EDUCAPES, B. em sinais. (2019). Aulas do curso Biociências em sinais. Educapes.capes.gov.br. https://educapes.capes.gov.br/handle/capes/431171

Francisco, G. da S., Militão, T., Campello, A. R. e S., \& Bourguignon, S. C. (2019). Biossegurança: manual bilíngue de barreira de Contenção Primária (EPI e EPC) Português e Libras. https://issuu.com/nuedisuff/docs/manual_de_biosseguran_a_5

Lebedeff, T. B., \& Santos, A. N. dos. (2014). Objetos de aprendizagem para o ensino de línguas: vídeos de curta-metragem e o ensino de Libras. Revista Brasileira de Linguística Aplicada, 14(4), 1073-1094. https://doi.org/10.1590/s1984-63982014005000020

Mercado, L. P. L. (2009). v. 21 n. 79 (2009): Integração de mídias nos espaços de aprendizagem | Em Aberto. rbep.inep.gov.br website: http://rbep.inep.gov.br/ojs3/index.php/emaberto/issue/view/214

Moraes, M. C., \& Torres, S. L. (2004). Sentipensar: fundamentos e práticas para reencantar a educação. Vozes.

Müller, I. C., \& Mastroeni, M. F. (2004). Tendência de Acidentes em Laboratório de pesquisa (33rd ed.). Revista Biotecnologia Ciência e Desenvolvimento.

Nagib, A., Aldemar, A., \& Castro, A. (1997). Capítulo 2 Revisão Sistemática da Literatura e Metanálise: a melhor forma de evidência para tomada de decisão em saúde e a maneira mais rápida de atualização terapêutica. In (pp. 12-15). http://www.centrocochranedobrasil.com.br/cms/apl/artigos/artigo_530.pdf

Nilo, T., Militão, T., \& Bourguignon, S. C. (2019). Biociências: Recurso de Tecnologia Assistiva (T.A.) para surdos. Trabalho de Conclusão de Curso de Ciências Biológicas: Universidade Federal Fluminense - UFF. Instituto de Biologia.

Oliveira, N., \& Júnior, W. D. (2011). O uso do vídeo como Ferramenta de Ensino aplicada em Biologia Celular Enciclopédia Biosfera, 7(13). https://conhecer.org.br/ojs/index.php/biosfera/article/view/4073

Pereira, A. L., \& Bachion, M. M. (2006). Atualidades em revisão sistemática de literatura, critérios de força e grau de recomendação de evidência. Rev gaúch enferm.

Souza, S. F., \& Silveira, H. (2011). (PDF) Terminologias do Conteúdo Químico em LIBRAS: Desafios na Aprendizagem de Estudantes Surdos. https://www.researchgate.net/publication/341941586_Terminologias_do_Conteudo_Quimico_em_LIBRAS_Desafios_na_Aprendizagem_de_Estudantes_Surd os

UOL, U. (2021, January 21). Nina lemos - "pandemia forte, máscara idem". na europa, máscara de pano não é indicada. www.uol.com.br website: https://www.uol.com.br/universa/colunas/nina-lemos/2021/01/21/mascara-fpp-ou-cirurgica-serao-obrigatorias-na-alemanha-e-as-de-tecido.htm

Viégas, S. R. C., \& Rehfeldt, M. J. H. (2017). Uso dos vídeos na formação continuada: integrando experiências de ensino de professores das regiões nordeste e sul. Imagens Da Educação, 7(2), 45-53. https://doi.org/10.4025/imagenseduc.v7i2.34593 